BMJ Open Sport \& Exercise Medicine

\section{Physical and functional outcomes following multidisciplinary residential rehabilitation for prearthritic hip pain among young active UK military personnel}

\author{
Russell J Coppack, ${ }^{1,2}$ James L Bilzon, ${ }^{2}$ Andrew K Wills, ${ }^{3}$ Ian M McCurdie, ${ }^{4}$ \\ Laura K Partridge, ${ }^{4}$ Alastair M Nicol, ${ }^{4}$ Alexander $\mathrm{N}$ Bennett ${ }^{1,5}$
}

To cite: Coppack RJ, Bilzon JL, Wills AK, et al. Physical and functional outcomes following multidisciplinary residential rehabilitation for prearthritic hip pain among young active UK military personnel. BMJ Open Sport Exerc Med 2016;2: $\mathrm{e} 000107$.

doi:10.1136/bmjsem-2015000107

- Prepublication history for this paper is available online. To view these files please visit the journal online (http://dx.doi.org/10.1136/ bmjsem-2015-000107).

Accepted 11 March 2016

CrossMark

For numbered affiliations see end of article.

Correspondence to Russell J Coppack; russ.coppack100@mod.uk

\section{ABSTRACT}

Background: There are no studies describing the clinical outcomes of a residential, multidisciplinary team (MDT) rehabilitation intervention for patients with prearthritic hip pain. The aim of this cohort study was to describe the functional and physical outcomes of multidisciplinary residential rehabilitation for UK military personnel with prearthritic hip pain.

Methods: Participants $(\mathrm{N}=40)$ with a mean age of 33 years referred to a specialist residential rehabilitation centre completed a comprehensive multidisciplinary residential intervention. The main outcome measures were mean pain, physical function (modified shuttle test (MST) and Y-balance test), hip range of motion (HROM) and a patient-reported outcome measure (The Copenhagen Hip and Groin Outcome Score, HAGOS).

All scores for symptomatic hips were taken at baseline and post-treatment.

Results: There were improvements in the Y-balance test and HROM following rehabilitation. There were significant improvements in mean difference (T1-to-T2) for Y-balance scores $(15.8 \mathrm{~cm}, 95 \% \mathrm{Cl} 10.7$ to 20.9 , $\mathrm{p}<0.001)$, HROM $\left(6.5^{\circ}\right.$ increase in hip flexion, $95 \% \mathrm{Cl}$ 4.6 to $9.4, p<0.001)$ and hip internal rotation $\left(4.6^{\circ}\right.$, $95 \% \mathrm{Cl} 2.7$ to $6.6, p<0.001)$. Scores for HAGOS, pain, MST and functional activity assessment showed no improvement.

Conclusions: Among UK military personnel with prearthritic hip pain, MDT residential rehabilitation resulted in improvements in a functional Y-balance test, hip flexion and internal rotation. The study suggests short-term benefits across some outcomes for the current UK military approach to MDT residential rehabilitation.

\section{INTRODUCTION}

Prearthritic hip disorders are abnormalities of the articulating surfaces of the acetabulum and femoral head before the onset of osteoarthritis (OA), including intra-articular structures such as the acetabular labrum and

\section{What are the new findings}

- We describe the clinical outcomes of multidisciplinary team residential rehabilitation on young active patients with prearthritic hip pain/femoroacetabular impingement.

- There was improvement in physical capacity measured by the $\mathrm{Y}$-balance test and hip range of motion.

chondral surfaces. ${ }^{1}$ Abnormalities of these structures can lead to biomechanical changes associated with significant hip pain and dysfunction in young adults. ${ }^{2} 3$ Femoroacetabular impingement (FAI) is recognised as a major cause of prearthritic hip pain in young active adults. ${ }^{5}$ FAI is characterised by impingement between the proximal end of the femur and acetabular rim caused by either an abnormally shaped femoral head (cam impingement) and/or an abnormally shaped acetabulum (pincer impingement). ${ }^{6} 7$ Abnormal femoroacetabular morphology is commonly seen in young men who make up much of the UK military

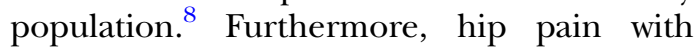
mechanical symptoms, particularly acetabular labral tears, are common symptoms presenting to the military orthopaedic surgeon. ${ }^{9}$

Hip arthroscopy and non-surgical interventions such as the treatments offered by physiotherapists, are recommended in the management of prearthritic FAI. ${ }^{1}{ }^{10-12}$ However, while single (unidisciplinary) treatments have been the subject of research, ${ }^{2} 1012$ there are no studies evaluating multidisciplinary team (MDT) programmes for the conservative treatment or postsurgical rehabilitation of prearthritic intra-articular 
hip disorders in young adults. Residential (inpatient) MDT rehabilitation for patients with musculoskeletal injuries has a long tradition in the UK military. Rehabilitation most often takes place in two clinical settings; outpatient primary care rehabilitation facilities (PCRFs), and inpatient residential centres including regional rehabilitation units (RRUs) and the UK Defence Medical Rehabilitation Centre (DMRC), Headley Court. Rehabilitation at the PCRF is focused primarily on physical function led by a physiotherapist, whereas residential centres have access to larger consultant-led MDTs delivering a broader biopsychosocial approach to treatment.

Despite the popularity and acceptance of residential MDT rehabilitation in the UK military, evidence supporting its effectiveness is lacking, and the extent to which outcomes differ between residential and outpatient approaches remains unknown. Therefore, the objective of our study was to describe the structure and process of a residential MDT intervention for UK military personnel with prearthritic hip pain and describe their associated clinical outcomes.

\section{METHODS}

\section{Setting}

The study was conducted at a specialist UK military rehabilitation centre.

\section{Study design}

We performed a retrospective cohort study. A review of the computerised clinical records was performed on military personnel admitted to the UK DMRC hip pain treatment programme. The intention of the observational study design was to describe and record the clinical outcomes of residential, multidisciplinary hip rehabilitation. Ethical approval was granted by the University of Bath Research Ethics Approval Committee for Health (REACH reference EP 15/16 87). In accordance with Ministry of Defence (MOD) research ethics guidelines, this study was exempt from requiring formal MOD ethical approval as it was categorised as a service evaluation. Approval for anonymised data extraction was granted in accordance with the local Caldicott guardian policy.

\section{Participants}

All UK military patients with clinical indicators of prearthritic, intra-articular hip pain attending DMRC for their first admission between October 2014 and May 2015 were included in the study. Clinical diagnoses were confirmed on imaging with $\mathrm{MRI} \pm \mathrm{MR}$ arthrogram prior to admission for rehabilitation (figure 1). X-ray was used to identify typical FAI features including cam and pincertype abnormalities. Patients were also included if they were admitted for treatment following arthroscopy for the management of acetabular labral tears. Participants comprised a mix of non-surgical and postsurgical patients completing concurrent residential treatment reflecting current UK military rehabilitation practice.

\section{Intervention}

All patients completed an intensive, goal-based multidisciplinary residential rehabilitation programme. Patients received treatment from Monday to Friday for $5 \mathrm{~h}$ /day over a 3-week period (mean (SD) duration 16.2 \pm 1.3 treatment days). The MDT consists of a consultant physician, physiotherapist, exercise rehabilitation instructor and occupational therapist. On admission, all patients underwent a comprehensive clinical assessment with each member of the MDT. The standardised treatment goals were to improve hip range of motion (HROM), improve 'global' hip strength, improve core and trunk muscle function, improve strength and neuromotor control of the deep hip stabiliser muscles, correct gait and balance deficits, control/reduce pain, improve function in daily living, and weight management. Active therapies included individually prescribed and group exercises, manual physiotherapy techniques, hydrotherapy/swimming, and patient education. Administration of non-steroidal anti-inflammatory drugs (NSAIDs) and analgesics were minimised where possible and controlled by the supervising lead consultant. The programme was individually tailored to each patient based on the findings of repeat assessments, weight-bearing status and response to treatment. All patients received a home-based exercise programme on discharge. Table 1 summarises the treatment intervention.

\section{Outcome measures}

Relevant descriptive, sociodemographic and disease-related information at the time of admission were recorded. The primary outcome was the change from admission (baseline) to discharge (3 weeks) in mean scores on a series of standardised, validated outcome measures assessing pain, physical function and occupational employability. Hip and groin disability was measured using the Copenhagen Hip and Groin Outcome Score (HAGOS) ${ }^{13}$ This self-report questionnaire is a quantitative measure of hip disability containing 37 questions covering six domains. Each question is answered on a Likert scale and each subscale is transformed and scored separately on a 100-point scale where $0=$ extreme problems and $100=$ no problems. The HAGOS has good-to-excellent test-retest reliability and responsiveness to change, ${ }^{14}$ and is specifically designed to assess hip disorders in young active adults similar to the UK military population. Hip pain was scored using a $100 \mathrm{~mm}$ horizontal visual analogue scale (VAS) where 0 represents no pain and 100 worst possible pain. A minimal clinically important difference is $18 \mathrm{~mm} .{ }^{15}$ The VAS has shown good internal consistency ${ }^{16}$ and has been extensively evaluated in clinical trials. ${ }^{16} 17$

Active HROM was measured for flexion and internal rotation using a $360^{\circ}$ goniometer. This is a standard assessment widely used in the clinical setting with high 
Medical Centre-Primary Care Rehabilitation Facility (PCRF)

Patient presents with Hip / groin pain that fails to respond to treatment; FAVlabral tear suspected

Assessment Clinic (MLAC) at Regional

Rehabilitation Unit (RRU)

RRU MIAC Assessment

- FAl +l- labral tear suspected

Investigations

-AP pelvis and lateral $\mathrm{x}$-ray and MRI hip to exclude other causes of hip pain/pathology. The MRI may identify labral tear or impingement at this stage.

-If MRI normal but features remain suggestive of labraltear/FAl then perform MR arthrogram (level of evidence 3; recommendation Grade B).

Diagnosis

-Clinical +/- radiological diagnosis of $\mathrm{FAl} /$ labral tear confirmed.

- Other causes excluded.

Treatment

-RRU or PCRF rehabilitation programme.

Severe symptoms with concern over diagnosis or no improvement in symptoms with rehabilitation

Refer forConsultant outpatient or MIAC reviewat the UK Defence Medical Rehabilitation Centre

- Other diagnoses excluded

-FAl / labral tear confirmed?

- Further specialist MDT residential rehabilitation at DMRC if appropriate

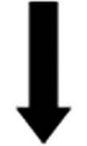

No improvement with specialist MDT

rehabilitation

DMRC referral - to experienced hip surgeon for assessment and diagnostic/therapeutic hip arthroscopy +1 proceed (level of evidence 4; recommendation C).

\author{
DMRC LowerLimb Consultant MIAC followup: \\ 2-months post-op \\ -Review \\ Post-op rehabilitation at DMRC / RRU / PCRF \\ Clinical and Functional Assessment \\ - Non arthritic hip score \\ -Functional Activity Assessment (FAA) \\ - Medical category and deployability \\ $6 \& 12$ months post op \\ Repeat clinical and functional assessment (above)
}

Figure 1 UK Defence Rehabilitation Hip Pain Care Pathway. AP anteroposterior; DMRC, Defence Medical Rehabilitation Centre; FAI, femoroacetabular impingement; MDT, multidisciplinary team; PCRF, primary care rehabilitation facility.

test-retest reliability values reported in participants with hip OA. ${ }^{18} 19$

Physical performance was measured using the modified $20 \mathrm{~m}$ shuttle test (MST). The MST ${ }^{20}$ involves walking and running at gradually increasing speeds until the patient is unable to continue. Speed is controlled by a series of paced-auditory cues accompanied by recorded verbal instructions. The MST ranges from level 0 $(0.66 \mathrm{~m} / \mathrm{s})$ to level $28(5 \mathrm{~m} / \mathrm{s})$. Thirty shuttles at level 28 is the highest level attainable before the test is terminated. The MST is preferred by military rehabilitation practitioners to the 6 min walk test ${ }^{21}$ because the incremental increase in speed mimics a military marching task. $^{22}$ Dynamic balance and postural control was measured using the modified star excursion balance test, known as the Y-balance test (figure 2). ${ }^{23}$ The Y-balance test was developed to incorporate those directional movements (anterior, posteromedial, posterolateral directions) with the greatest accuracy in identifying lower extremity dysfunction. ${ }^{24}$ The supervising therapist measures the maximum distance in centimetres the patient can reach with the free limb while balancing on the contralateral limb. Scores for all three movements were combined to provide a single composite measure of dynamic balance. The test is a highly reliable tool to measure dynamic balance, ${ }^{25}$ and is currently used by the UK military. 
Table 1 Multidisciplinary team residential hip rehabilitation programme-components of treatment

\begin{tabular}{|c|c|c|c|}
\hline $\begin{array}{l}\text { Treatment } \\
\text { modality }\end{array}$ & Treatment content & Treatment goals & $\begin{array}{l}\text { Frequency per } \\
\text { week (duration) }\end{array}$ \\
\hline Group exercise & $\begin{array}{l}\text { Strengthening exercises, active range of } \\
\text { motion exercises, functional balance drills, } \\
\text { gait drills, progressive coordination drills, } \\
\text { non-weight-bearing aerobic /endurance } \\
\text { exercise, minor team games }\end{array}$ & $\begin{array}{l}\text { Restore strength of deep hip } \\
\text { stabilisers, improve core strength, } \\
\text { increase joint range of motion, improve } \\
\text { balance and neuromotor control, } \\
\text { improve muscle endurance, promote } \\
\text { group cohesion and social support }\end{array}$ & 12 (30-45 min) \\
\hline $\begin{array}{l}\text { Individual } \\
\text { physiotherapy* }\end{array}$ & $\begin{array}{l}\text { Manual therapy techniques, muscle } \\
\text { activation and timing patterns, active and } \\
\text { passive range of motion exercises, advice } \\
\text { on home exercise, gait re-education training }\end{array}$ & $\begin{array}{l}\text { Improve quality and timing of } \\
\text { movement, improve muscle strength, } \\
\text { reduce pain, increase joint range of } \\
\text { motion, induce relaxation, promote } \\
\text { normal walking gait }\end{array}$ & 5 (30 min) \\
\hline $\begin{array}{l}\text { Hydrotherapy/ } \\
\text { swimming }\end{array}$ & $\begin{array}{l}\text { Non-weight-bearing aerobic exercise, } \\
\text { strengthening exercises, active range of } \\
\text { motion exercises, self-paced recreational } \\
\text { swimming, progressive/assisted } \\
\text { weight-bearing exercise and activity }\end{array}$ & $\begin{array}{l}\text { Improve muscle strength, improve } \\
\text { aerobic capacity, increase joint range } \\
\text { of motion, improve confidence in } \\
\text { weight bearing, induce relaxation, } \\
\text { promote enjoyment and variety of } \\
\text { treatment }\end{array}$ & $3(60 \mathrm{~min})$ \\
\hline $\begin{array}{l}\text { Individual } \\
\text { occupational } \\
\text { therapy }\end{array}$ & $\begin{array}{l}\text { Relaxation techniques, postural } \\
\text { re-education, cognitive-behavioural therapy } \\
\text { techniques, self-help coping strategies, pain } \\
\text { management }\end{array}$ & $\begin{array}{l}\text { Induce relaxation, promote behavioural } \\
\text { change, control pain, correct/improve } \\
\text { poor posture }\end{array}$ & 3 (60 min) \\
\hline Patient education & $\begin{array}{l}\text { Coping with pain, benefits of exercise, joint } \\
\text { protection, anatomy and pathology of hip } \\
\text { pain, nutrition }\end{array}$ & $\begin{array}{l}\text { Activity modification, reduction of pain, } \\
\text { promote behavioural change, weight } \\
\text { management, improve knowledge of } \\
\text { treatment options, improve ability to } \\
\text { relax, improve knowledge of self-help } \\
\text { techniques }\end{array}$ & $2(60 \mathrm{~min})$ \\
\hline
\end{tabular}

Occupational employability was assessed using the functional activity assessment (FAA). ${ }^{26}$ The FAA is a single-item, five-point ordinal measure developed to assess occupational outcome in military rehabilitation (table 2). The validity of the patient-reported FAA has been tested on our military patient population at DMRC and reported in the scientific literature. ${ }^{26} 27$ All outcome measures were recorded at baseline (pretreatment) and at 3 weeks (post-treatment) by a trained member of the MDT.

\section{Statistical analysis}

For participants with bilateral hip pain, HROM and Y-balance scores were summed (eg, right score+left
A

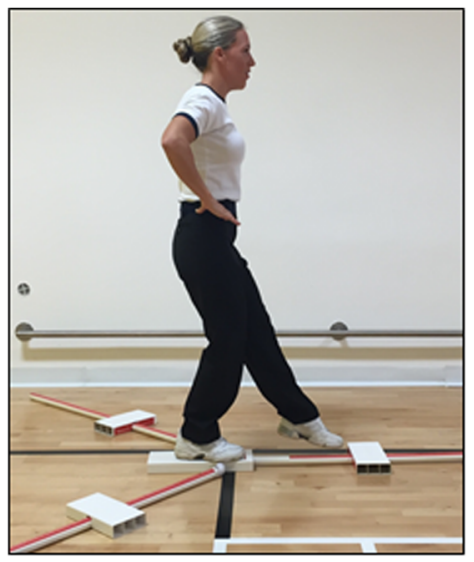

B

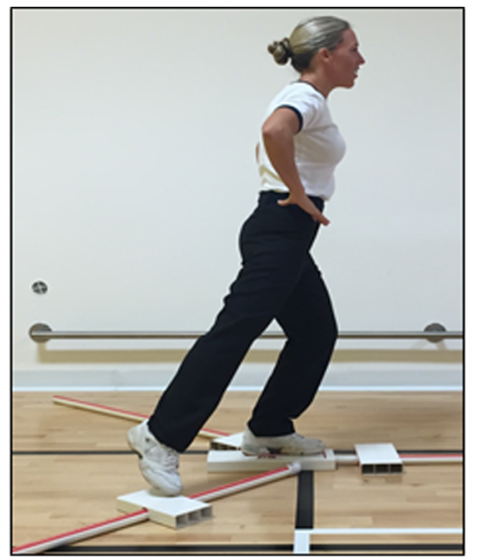

C

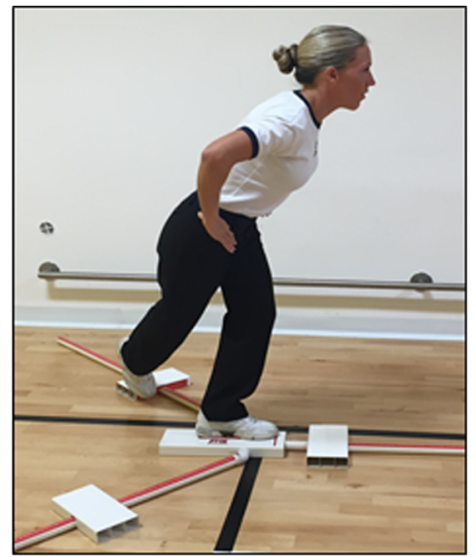

Figure 2 Y-balance test. From a single-leg stance the participant reaches the freely moveable limb along a line in the anterior $(A)$, posterolateral $(B)$ and posteromedial $(C)$ directions. 
Table 2 FAA code and description

\begin{tabular}{|c|c|c|c|}
\hline Code & Grade & Royal Navy description & Army/RAF description \\
\hline FAA 1 & Fully fit & Fully fit, field or seas worldwide & $\begin{array}{l}\text { Can do all aspects of their job and all general } \\
\text { military duties }\end{array}$ \\
\hline FAA 2 & $\begin{array}{l}\text { Fit for trade and fit for } \\
\text { restricted general or } \\
\text { military duties }\end{array}$ & Fit for flying, aircrew duties & $\begin{array}{l}\text { Able to do all aspects of their primary task but not } \\
\text { all the physical aspects of their physical duties (this } \\
\text { might apply to a clerk but is unlikely to apply to an } \\
\text { infantry soldier) }\end{array}$ \\
\hline FAA 3 & $\begin{array}{l}\text { Unfit for trade but fit for } \\
\text { restricted general or } \\
\text { military duties }\end{array}$ & $\begin{array}{l}\text { Fully employable ashore/ship in } \\
\text { harbour or ashore only in own } \\
\text { trade/skill at sea } \\
\text { Fit for limited flying aircrew duties }\end{array}$ & $\begin{array}{l}\text { Unable to do primary task but able to perform } \\
\text { some limited physical tasks (eg, aircraft engineer } \\
\text { who cannot perform his trade but can do some } \\
\text { other physical duties or an infantryman who can } \\
\text { work in MT or stores) }\end{array}$ \\
\hline FAA 4 & $\begin{array}{l}\text { Unfit for all but sedentary } \\
\text { duties }\end{array}$ & $\begin{array}{l}\text { Employable in restricted duties } \\
\text { ashore only }\end{array}$ & Only able to perform light duties \\
\hline FAA 5 & Off all duties & Off all duties (ashore sick leave) & On sick leave, Y-listed or non-effective \\
\hline
\end{tabular}

FAA, functional activity assessment; MT, mechanical transport; RAF, Royal Air Force.

score/2) to provide an aggregate score for internal rotation, flexion and dynamic balance pre-to-post treatment. All continuous variables were assessed using the Kolmogorov-Smirnov test and an examination of histograms and their skewness and kurtosis ${ }^{28}$; none were considered to deviate from normality. Descriptive statistics were calculated for the whole sample. Continuous variables are presented as means and SD, and categorical variables are presented by frequencies and percentages. Within group changes over time were analysed using a paired $\mathrm{t}$ test. Ordinal data for the FAA employability scale were assessed using the Wilcoxon signed rank test. Statistical calculations were performed using SPSS (V.21.0.0, SPSS Inc, Chicago, Illinois, USA).

\section{RESULTS}

\section{Participant characteristics}

The demographic and baseline patient characteristics are presented in table 3 . Forty UK military patients (27 $(67.5 \%)$ male) with a mean age of 32.8 years (SD 7.1), range $20-50$ years, were included in the study. The distribution of patients by military branch was $26(65 \%)$ Army, 10 (25\%) Royal Air Force (RAF) and 4 (10\%) Royal Marines (RM). The patient distribution by rank seniority was $23(57.5 \%)$ junior ranks, $10(25 \%)$ senior ranks and $7(17.5 \%)$ officer rank. Nineteen $(47.5 \%)$ patients had undergone arthroscopic repair for a labral tear, and $29(72.5 \%)$ had completed a previous course of inpatient treatment at a RRU.

\section{Main outcome measures}

The main treatment effects (paired $\mathrm{t}$ test) for all outcome measures are presented in table 4 .

\section{Physical and functional outcome measures (Y-balance,} HROM, MST)

The change in Y-balance test score over time was statistically significant. The mean (SD) pretreatment and posttreatment scores for Y-balance were 240.5 (26.9) $\mathrm{cm}$ and
$256.3(20.8) \mathrm{cm}$, respectively. The mean improvements of $15.8 \mathrm{~cm}$ showed a significant increase $(\mathrm{p}<0.001)$ in Y-balance score (95\% CI 10.7 to 20.9). The HROM scores (flexion and internal rotation) also revealed significant improvements over the period of treatment. The mean (SD) scores for flexion improved by $6.5^{\circ}$ (95\% CI 4.6 to $9.4, \mathrm{p}<0.001)$ from $110.2^{\circ}(24.3)$ at baseline to $116.7^{\circ}$ (23.3) at week 3. The mean (SD) scores for internal rotation improved by $4.6^{\circ}(95 \%$ CI 2.7 to $6.6, \mathrm{p}<0.001)$ from $25.2^{\circ}(13.7)$ at baseline to $29.8^{\circ}(12.4)$ at week 3 . There were no pre-to-post treatment differences in the MST scores. The mean (SD) test scores achieved were level 10.3 (4.9) at baseline and level 10.5 (5.1) at week 3 . The small mean difference of 0.2 levels was not statistically different from baseline $(95 \% \mathrm{CI}-1.2$ to $0.7, \mathrm{p}=0.59)$.

\section{Patient-reported outcomes (pain, HAGOS)}

The pre-to-post treatment scores for changes in pain were not significant. The baseline mean (SD) VAS was 36.3 (24.2) $\mathrm{mm}$ and post-treatment score was 34.8 (22.3) $\mathrm{mm}$. The mean difference was a $1.5 \mathrm{~mm}$ reduction in pain after treatment $(95 \%$ CI -0.49 to $8.0, \mathrm{p}=0.63)$. There were no significant pre-to-post treatment improvements in scores on any of the HAGOS subscales. Table 4 and figure 3 shows that five out of six subscale domains deteriorated over the period of treatment based on the patients self-ratings.

\section{Occupational employability (FAA)}

The median score on the FAA occupational employability index did not change from pretreatment $(\mathrm{Md}=3.0)$ to post-treatment $(\mathrm{Md}=3.0), \mathrm{p}=0.13$.

There were no between-group differences for any outcome measure in the surgical versus non-surgical, or male versus female subgroups.

\section{DISCUSSION}

In this first study of a short-term MDT residential rehabilitation intervention in military personnel with 
Table 3 Baseline descriptive characteristics of study participants $(\mathrm{N}=40)$

\begin{tabular}{|c|c|c|c|}
\hline Variable/characteristic & Male $(n=27)$ & Female $(n=13)$ & Total $(n=40)$ \\
\hline Age, year, mean (SD) & $32.8(7 \cdot 1)$ & $32.9(3.8)$ & $32 \cdot 8(7 \cdot 1)$ \\
\hline Height, cm, mean (SD) & $178.4(5 \cdot 3)$ & $169 \cdot 3(3 \cdot 2)$ & $175.4(6.4)$ \\
\hline Weight, kg, mean (SD) & $81.8(11.5)$ & $75.9(16.9)$ & $79.7(13.5)$ \\
\hline Body mass index, $\mathrm{kg} / \mathrm{m}^{2}$, mean (SD) & $25.5(3.5)$ & $26.5(6 \cdot 1)$ & $25.8(4.5)$ \\
\hline Treatment duration, days, mean (SD) & $16 \cdot 2(1 \cdot 3)$ & $16 \cdot 1(1 \cdot 2)$ & $16 \cdot 2(1 \cdot 3)$ \\
\hline \multicolumn{4}{|l|}{ Service branch, N (\%) } \\
\hline Army & $18(66 \cdot 7)$ & $8(61.5)$ & $26(65 \cdot 0)$ \\
\hline RAF & $5(18.5)$ & $5(38.5)$ & $10(25 \cdot 0)$ \\
\hline $\mathrm{RM}$ & $4(14 \cdot 8)$ & $0(0 \cdot 0)$ & $4(10 \cdot 0)$ \\
\hline \multicolumn{4}{|l|}{ Rank seniority, N (\%) } \\
\hline Junior rank & $15(55 \cdot 5)$ & $8(61.5)$ & $23(57.5)$ \\
\hline Senior rank & $8(29 \cdot 7)$ & $2(15.5)$ & $10(25 \cdot 0)$ \\
\hline Officer rank & $4(14 \cdot 8)$ & $3(23 \cdot 0)$ & $7(17.5)$ \\
\hline \multicolumn{4}{|l|}{ Diagnosis, N (\%) } \\
\hline FAl/acetabular labral tear (right) & $7(25 \cdot 9)$ & $6(46 \cdot 2)$ & $13(32 \cdot 5)$ \\
\hline FAl/acetabular labral tear (left) & $7(25 \cdot 9)$ & $3(23 \cdot 0)$ & $10(25.0)$ \\
\hline FAl/acetabular labral tear (bilateral) & $3(11 \cdot 1)$ & $3(23.0)$ & $6(15 \cdot 0)$ \\
\hline Other hip pain diagnosis & $10(37 \cdot 0)$ & $1(7 \cdot 8)$ & $11(27.5)$ \\
\hline \multicolumn{4}{|l|}{ Previous surgery, N (\%) } \\
\hline Arthroscopy & $7(26 \cdot 0)$ & $12(92 \cdot 3)$ & $19(47.5)$ \\
\hline 'Other' surgery & $7(26 \cdot 0)$ & $0(0.0)$ & $7(17.5)$ \\
\hline No surgery & $13(48 \cdot 1)$ & $1(7 \cdot 7)$ & $14(35 \cdot 0)$ \\
\hline \multicolumn{4}{|l|}{ Previous treatment, $N(\%)$} \\
\hline \multicolumn{4}{|l|}{$\mathrm{RRU}$} \\
\hline Yes & $21(77 \cdot 7)$ & $8(61.5)$ & $29(72.5)$ \\
\hline No & $6(22 \cdot 2)$ & $5(38.5)$ & $11(27.5)$ \\
\hline \multicolumn{4}{|l|}{ PCRF } \\
\hline Yes & $25(92 \cdot 6)$ & $11(84 \cdot 6)$ & $36(90 \cdot 0)$ \\
\hline No & $2(7.4)$ & $2(15.4)$ & $4(10 \cdot 0)$ \\
\hline \multicolumn{4}{|l|}{ Medication, N (\%) } \\
\hline Yes & $20(74.0)$ & $11(84 \cdot 6)$ & $31(77.5)$ \\
\hline No & $7(26 \cdot 0)$ & $2(15.4)$ & $9(22.5)$ \\
\hline
\end{tabular}

FAI, femoroacetabular impingement; PCRF, primary care rehabilitation facility; RAF, Royal Air Force; RM, Royal Marines; RRU, regional rehabilitation unit.

prearthritic hip pain, we report improved HROM and dynamic balance test scores. There was no evidence for a change in outcome scores for the patient-reported HAGOS subscales, pain, MST and FAA employability scale.

How do these results compare with other studies?

The results from our study are inconsistent with the findings of two recent publications reporting HROM, pain and functional outcomes following conservative treatment of prearthritic hip disorders. ${ }^{12}$ Both studies employed a within-group observational design similar to the present study, and a comparable population in terms of sample size, mean age, diagnostic inclusion criteria, and baseline pain-related and function-related impairment. Fundamental to all three programmes was an exercise-based regimen augmented by education, advice on activity modification and manual physiotherapy. Hunt et $a l^{1}$ found significant improvements in pain (numeric pain scale), physical function (Western Ontario and McMaster Universities Arthritis (WOMAC) index; nonarthritic hip score (NAHS)) and quality of life (Short
Form-12) in patients with prearthritic, intra-articular hip pain completing a directed course of conservative treatment. Emara $e t a l^{12}$ showed a stage-based physical therapy programme-improved pain symptoms and patientreported function (Modified Harris Hip Score (MHHS)), but had no effect on HROM, in 33 patients with FAI up to 28 months after treatment. This contradicts our findings showing significant post-treatment improvement in patients HROM (minimal clinically important difference, $\left.5^{\circ}\right),{ }^{29}$ with no change in pain or patient-reported function measured by the HAGOS.

Between-study differences in outcome measures (MHHS; NAHS; WOMAC; HAGOS), time to follow-up (3 weeks; 12 months; 28 months) and residential versus outpatient settings may explain the inconsistencies in results. The observational design of our study limits the conclusions that can be drawn concerning the causal effects of treatment on rehabilitation outcomes. Further high-quality randomised trials investigating longer term effects of rehabilitation with our military population are required. This is particularly important as there may be a delayed period of adaptation before reductions in pain 
Table 4 Pre-to-post rehabilitation mean differences (paired t test) for all outcomes

\begin{tabular}{|c|c|c|c|c|}
\hline Outcome measure & Pretreatment mean (SD) & Post-treatment mean (SD) & Difference, mean (95\% Cl) & p Value \\
\hline Y-balance* & $240.5(26.9)$ & $256.3(20.8)$ & 15.8 (10.7 to 20.9$)$ & $<0.001$ \\
\hline HROM (flexion)* & $110.2(24.3)$ & 116.7 (23.3) & 6.5 (4.6 to 9.4$)$ & $<0.001$ \\
\hline HROM (internal rot)* & $25.2(13.7)$ & $29.8(12.4)$ & $4.6(2.7$ to 6.6$)$ & $<0.001$ \\
\hline Modified shuttle test & $10.3(4.9)$ & $10.5(5.1)$ & $0.2(-1.2$ to 0.7$)$ & 0.60 \\
\hline $\begin{array}{l}\text { Pain (VAS } 1-100 \mathrm{~mm} \text { ) } \\
\text { HAGOS subscales } \dagger\end{array}$ & $36.3(24.2)$ & $34.8(22.8)$ & $1.5(-0.5$ to 8.0$)$ & 0.63 \\
\hline Pain & $37.7(20.9)$ & $35.1(23.7)$ & $2.6(-1.5$ to 6.8$)$ & 0.21 \\
\hline Symptoms & $45.8(23.2)$ & $46.3(24.2)$ & $0.5(-4.9$ to 4.1$)$ & 0.83 \\
\hline ADL & $32.2(24.1)$ & $31.0(24.7)$ & $1.2(-2.1$ to 4.7$)$ & 0.46 \\
\hline Sport/recreation & $51.0(28.1)$ & $48.5(28.6)$ & $2.5(-2.1$ to 7.1$)$ & 0.28 \\
\hline PA & $84.7(24.9)$ & $77.5(31.2)$ & $7.2(0.0$ to 14.4$)$ & 0.05 \\
\hline QOL & $69.5(20.4)$ & $64.9(23.3)$ & $4.6(-0.5$ to 9.7$)$ & 0.08 \\
\hline
\end{tabular}

are realised following 3 weeks of intensive rehabilitation, which appears to have stimulated improvements in dynamic balance and HROM.

When considering the structure and process of rehabilitation, comparisons between our study and other similar studies are extremely limited due to the lack of published research focusing on MDT residential treatment for prearthritic hip pain. In terms of structure, the most relevant findings are reported in patients with hip OA. Angst $e t a l^{30}$ found a comprehensive 3-week residential rehabilitation intervention led to statistically and clinically important improvements in pain and function (WOMAC) for patients with comorbid hip pain. In an older study, Weigl et $a l^{31}$ reported improvements in pain and physical function at 2-year follow-up in 44 patients with hip OA completing a 3-4-week residential programme.

The duration and content of treatment in our study closely approximates those utilised by Angst and colleagues and Weigl and colleagues (eg, 3 weeks group

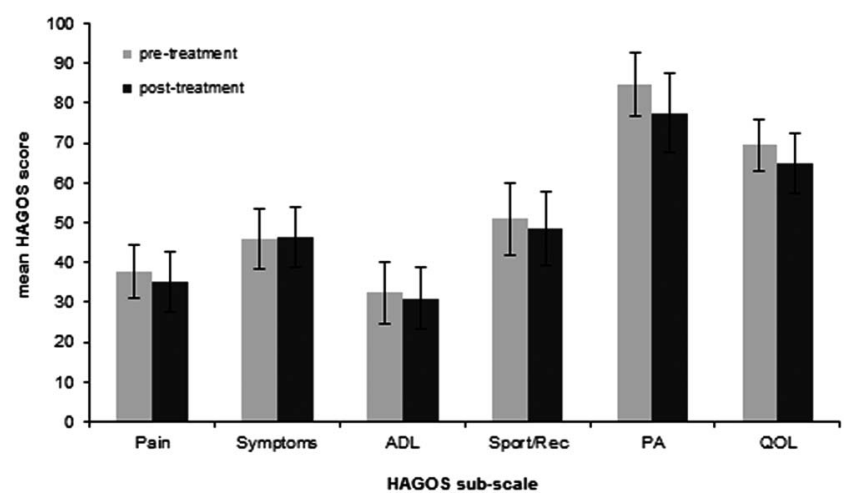

Figure 3 Participants ( $\mathrm{N}=40)$ mean Copenhagen Hip and Groin Outcome Score (HAGOS) pre-to-post treatment. Total score for each subscale is summed and transformed such that $100=$ best score (no problems) and $0=$ worst score (extreme problems). Data are presented as mean $(95 \% \mathrm{Cl})$. exercise, individual physiotherapy, patient education, NSAIDs); however, we did not observe similar improvements in patients' pain and function following residential treatment. The composition of the MDT, study population and treatment outcomes differed between studies, and a potential reason for the discrepancies between our findings and those of previous studies is the heterogeneity with respect to participant case mix, outcome measures, treatment setting (hospital vs specialist rehabilitation centre) and MDT size and composition. These methodological inconsistencies must be addressed to allow a better understanding of the benefits of MDT residential rehabilitation for prearthritic hip pain.

Patient-reported outcomes (PROs) are considered the gold standard when measuring the patient's perspective of treatment efficacy. ${ }^{32}$ The HAGOS did not demonstrate any significant pre-to-post treatment improvements in our study. This PRO is used in the UK military hip rehabilitation pathway because it was developed for physically active young-to-middle-aged adults with hip and/or groin pain, ${ }^{14}$ and is designed to assess treatmentinduced changes from week-to-week. ${ }^{33}$ However, while the HAGOS subscales have shown good test-retest reliability and responsiveness in athletic populations, ${ }^{14} 3334$ its performance in a military population is unknown, and it is possible this scoring system fails to address activities of most relevance to Armed Forces personnel. Studies reporting clinically meaningful changes in other PROs following hip rehabilitation used a minimum 6-week period between tests. ${ }^{35} 36$ The reference values of the HAGOS over longer testing periods with a military population need to be established.

The primary aim of UK military rehabilitation is to return personnel fit to undertake their technical trade and general duties. ${ }^{26}$ Therefore, outcome measures providing information on a patient's military-specific occupational status are important. The FAA scores showed the same median rating of 3.0 (unfit for trade but fit for 
restricted general or military duties) before and after treatment. The FAA has shown adequate construct and concurrent validity as a surrogate measure of physical health ${ }^{27}$; however, our results suggest its ability to track changes in employment status following a single residential admission period is unproven.

\section{Study limitations}

Despite the novelty of these findings, they must be considered in the light of limitations of the study design. It is a retrospective cohort study with no control group. This limits the conclusions that can be drawn on the effectiveness of our rehabilitation programme. Although improvement in symptoms and function could be a result of treatment, a control group is needed to gain a causal estimate of the effect of rehabilitation. Prospective studies employing a randomised controlled design should be undertaken to compare available treatment options. The lack of follow-up beyond 3 weeks would not capture any longer term benefits of rehabilitation which may explain the non-significant findings for some outcomes in our study. Therefore, we have restricted our comments to the 3-week period of rehabilitation and do not speculate on the long-term benefits of MDT residential rehabilitation. Future studies should address longer term compliance to and effectiveness of conservative treatment. While the use of a welldefined military population may limit the generalisability of our results to other populations and settings, we believe the findings may also be relevant to young active sportsmen and women. Our patients underwent rehabilitation at varying stages of their recovery, and while this approach mimics our clinical practice, some heterogeneity in clinical severity of the sample may have attenuated the treatment effect. Finally, we did not record psychological variables (eg, anxiety, irritability, depression) that may be related to pain. ${ }^{22}$ Notwithstanding these limitations, the observational design did provide the opportunity to obtain data with a young active cohort, and document the acute responses to treatment reflecting the clinical reality of a military rehabilitation setting.

\section{CONCLUSIONS}

With increased pressure to ensure military personnel remain fit for operations against the backdrop of reductions in manpower, it is expected that intensive residential rehabilitation will become an increasingly important component of future healthcare provision in the UK Armed Forces. This is particularly important given recent increases in operational deployments and the commensurate increase in occupational exposure associated with loaded marching. This study is the first to report outcomes of MDT residential rehabilitation in a military cohort with prearthritic hip pain.

Comprehensive residential treatment showed evidence of improvements in a functional capacity (Y-balance) test and HROM (flexion, internal rotation). The intervention did not confer any benefits on pain, the patientreported HAGOS, or occupational employability (FAA). The study is strongly suggestive of some short-term benefits for the current UK military approach to MDT residential rehabilitation in the management of prearthritic hip pain. Further studies should adopt longer follow-up observations, evaluating longer term adaptations and assessing compliance to post-residential treatment plans. There is a clear need for further research using randomised designs examining MDT residential rehabilitation against other treatment options to ensure patients receive treatment in the optimal clinical setting. Future studies should also focus on the measurement properties of hip PROs with a military population.

\section{Author affiliations}

${ }^{1}$ Academic Department of Military Rehabilitation, Defence Medical

Rehabilitation Centre (DMRC), Epsom, UK

${ }^{2}$ Department for Health, University of Bath, Bath, UK

${ }^{3}$ School of Clinical Sciences, University of Bristol, Bristol, UK

${ }^{4}$ Centre for Lower Limb Rehabilitation, Defence Medical Rehabilitation Centre (DMRC), Epsom, UK

${ }^{5}$ Leeds Institute of Rheumatic and Musculoskeletal Medicine, University of Leeds, Leeds, UK

Acknowledgements The authors wish to thank Major James Watson, Captain Paul Thompson and all the staff and patients on the Centre for Lower Limb Rehabilitation at DMRC Headley Court for their assistance with this study.

Contributors RJC designed the study, conducted the initial analysis, drafted the initial manuscript and approved the final manuscript as submitted. JLB, AKW and ANB supervised the conduct of the study, assisted with data analysis, reviewed and revised the manuscript, and approved the final manuscript as submitted. IMM, AMN and LKP collected the data, reviewed and revised the manuscript, and approved the final manuscript as submitted.

Funding This trial is the first in a series comprising the Military Hip Rehabilitation Outcome (MILO) Study. The MILO study is supported financially by the Arthritis Research UK Centre for Sport, Exercise and Osteoarthritis (Grant reference 20194).

Competing interests None declared.

Ethics approval The University of Bath Research Ethics Approval Committee for Health (REACH).

Provenance and peer review Not commissioned; internally peer reviewed.

Data sharing statement No additional data are available.

Open Access This is an Open Access article distributed in accordance with the Creative Commons Attribution Non Commercial (CC BY-NC 4.0) license, which permits others to distribute, remix, adapt, build upon this work noncommercially, and license their derivative works on different terms, provided the original work is properly cited and the use is non-commercial. See: http:// creativecommons.org/licenses/by-nc/4.0/

\section{REFERENCES}

1. Hunt D, Prather $H$, Harris-Hayes $M$, et al. Clinical outcomes analysis of conservative and surgical treatment of patients with clinical indications of pre-arthritic, intra-articular hip disorders. Am Acad Phys Med Rehabil 2012;4:479-87.

2. Diamond LE, Dobson FL, Bennell KL, et al. Physical impairments and activity limitations in people with femoroacetabular impingement: a systematic review. Br J Sports Med 2015;49:230-42.

3. Beck M, Kalhor M, Leunig M, et al. Hip morphology influences the pattern of damage to the acetabular cartilage: femoroacetabular impingement as a cause of early osteoarthritis of the hip. J Bone Joint Surg Br 2005;87:1012-18. 
4. Byrd JW. Femoroacetabular impingement in athletes: current concepts. Am J Sports Med 2014;42:737-51.

5. Loudon JK, Reiman MP. Conservative management of femoroacetabular impingement (FAI) in the long distance runner. Phys Ther Sport 2014;15:82-90.

6. Keogh MJ, Batt ME. A review of femoroacetabular impingement in athletes. Sports Med 2008;38:863-78.

7. Pollard TCB. A perspective on femoroacetabular impingement. Skeletal Radiol 2011;40:815-18.

8. Hack K, Di Primio G, Rakhra K, et al. Prevalence of cam-type femoroacetabular impingement morphology in asymptomatic volunteers. J Bone Joint Surg Am 2010;92:2436-44.

9. Murphy KP, Freedman BA, Giuliani JG. Arthroscopic management of intra-articular hip disorders in active-duty military patients. Oper Tech Sports Med 2005;13:143-9.

10. Spencer-Gardner L, Eischen JJ, Levy BA, et al. A comprehensive five-phase rehabilitation programme after hip arthroscopy for femoroacetabular impingement. Knee Surg Sports Trumatol Arthrosc 2014;22:848-59.

11. Wall PD, Fernandez M, Griffin DR, et al. Nonoperative treatment for femoroacetabular impingement: a systematic review of the literature. PM R 2013;5:418-26.

12. Emara K, Samir W, Motasem EH, et al. Conservative treatment for mild femoroacetabular impingement. J Orthop Surg (Hong Kong) 2011;19:41-5.

13. Thorborg K, Hölmich P, Christensen R, et al. The Copenhagen hip and groin outcome score (HAGOS): development and validation according to the COSMIN checklist. Br J Sports Med 2011:45:478-91.

14. Hinman RS, Dobson F, Takla A, et al. Which is the most useful patient-reported outcome in femoroacetabular impingement? Test-retest reliability of six questionnaires. $\mathrm{Br} J$ Sports Med 2014;48:458-63.

15. Bennell KL, Egerton T, Martin J, et al. Effect of physical therapy on pain and function in patients with hip osteoarthritis: a randomized clinical trial. JAMA 2014;311:1987-97.

16. Mohtadi NGH, Griffin DR, Pedersen ME, et al. The development and validation of a self-administered quality-of-life outcome measure for young, active patients with symptomatic hip disease: the international hip outcome tool (iHOT-33). Arthroscopy 2012;28:595-605.

17. Collins SL, Moore RA, McQuay HU. The visual analogue pain intensity scale: what is moderate pain in millimetres? Pain 1997;72:95-7.

18. French HP, Cusack T, Brennan A, et al. Exercise and manual physiotherapy arthritis research trial (EMPART) for osteoarthritis of the hip: a multicenter randomised controlled trial. Arch Phys Med Rehabil 2013;96:302-14.

19. Holm I, Bolstad B, Lutken T, et al. Reliability of goniometric measurements and visual estimates of hip ROM in patients with osteoarthrosis. Physiother Res Int 2000;5:241-8.

20. Hassett LM, Harmer AR, Moseley AM, et al. Validity of the modified 20-metre shuttle test: assessment of cardiorespiratory fitness in people who have sustained a traumatic brain injury. Brain Inj 2007;21:1069-77.
21. Balke B. A simple field test for the assessment of physical fitness. Rep Civ Aeromed Res Inst US 1963;53:1-8.

22. Roberts AJ, Seah R, Dickens JC, et al. A comparison of pain levels after the Biering-Sorensen and the modified 20-metre shuttle test in patients with chronic low back pain. J Back Musculoskelet Rehabil 2014;27:173-9.

23. Hertel J, Braham RA, Hale SA, et al. Simplifying the star excursion balance test: analyses of subjects with and without chronic ankle instability. J Orthop Sports Phys Ther 2006;36:131-7.

24. Hegedus EJ, Stern B, Reiman MP, et al. A suggested model for physical examination and conservative treatment of athletic pubalgia. Phys Ther Sport 2013;14:3-16.

25. Hyong $\mathrm{IH}, \mathrm{Kim} \mathrm{JH}$. Test of intrarater and interrater reliability for the star excursion balance test. J Phys Ther Sci 2014;26:1139-41.

26. Roberts A, Franklyn-Miller A, Etherington J. A new functional outcome assessment tool for military musculoskeletal rehabilitation: a pilot validation study. Phys Med Rehabil 2011;3:527-32.

27. Roberts AJ, Etherington J. The functional activity assessment: a validated PROM, unreliable in the hands of clinicians. J R Army Med Corps 2013;159:287-90.

28. Kim HY. Statistical notes for clinical researchers: assessing normal distribution (2) using skewness and kurtosis. Restor Dent Endod 2013;38:52-4

29. Cibulka MT, White DM, Woehrle J, et al. Hip pain and mobility deficits-hip osteoarthritis: clinical practice guidelines linked to the international classification of functioning, disability, and health from the orthopaedic section of the American Physical Therapy Association. J Orthop Sports Phys Ther 2009;39:A1-25.

30. Angst F, Verra ML, Lehmann S, et al. Effects of inpatient rehabilitation in hip and knee osteoarthritis: a naturalistic prospective cohort study with intraindividual control of effects. Arch Phys Med Rehabil 2013;94:2139-45.

31. Weigl M, Angst F, Stucki G, et al. Inpatient rehabilitation for hip or knee osteoarthritis: 2 year follow up study. Ann Rheum Dis 2004;63:360-8.

32. Thorborg K, Tijssen M, Habets B, et al. Patient-reported outcome (PRO) questionnaires for young-aged to middle-aged adults with hip and groin disability: a systematic review of the clinimetric evidence. Br J Sports Med 2015;49:812.

33. Harris-Hayes M, McDonough CM, Leunig M, et al. Clinical outcomes assessment in clinical trials to assess treatment of femoroacetabular impingement: use of patient-reported outcome measures. J Am Acad Orthop Surg 2013;21(Suppl 1):S39-46.

34. Thomeé $\mathrm{R}$, Jónasson $\mathrm{P}$, Thorborg $\mathrm{K}$, et al. Cross-cultural adaptation to Swedish and validation of the Copenhagen hip and groin outcome score (HAGOS) for pain, symptoms and physical function in patients with hip and groin disability due to femoro-acetabular impingement. Knee Surg Sports Traumatol Arthrosc 2014;22:835-42.

35. Mahomed NN, Davis AM, Hawker GB, et al. Inpatient compared with home-based rehabilitation following primary unilateral total hip or knee replacement: a randomized controlled trial. J Bone Joint Surg Am 2008;90:1673-80.

36. Harmer AR, Naylor JM, Crosbie J, et al. Land-based versus water-based rehabilitation following total knee replacement: a randomized, single-blind trial. Arthritis Rheum 2009;61:184-91. 